\title{
Analysis of the Causes and Countermeasures of English Lexical Petrification
}

\author{
Youya Zhou \\ Nanchang Institute of Technology, Nanchang, 330099
}

\section{Keywords: Lexical petrification; Causes; Countermeasures}

\begin{abstract}
Vocabulary is the building material of language, which is the main basis for the survival and development of language system. Away from the word, the language will lose the practical significance. No grammar, a lot of things can not be passed; no words, then nothing can be transmitted. For English learners, the number of vocabulary and the level of vocabulary directly affect the comprehensive development of their ability of listening, speaking, reading and writing. Therefore, vocabulary learning is a very important part of English learning process, going through the whole process of English learning. However, although many students put a lot of time and effort in the vocabulary learning, but the effect is not ideal, especially in the speaking, writing and translation. The deficiency of language output ability is more prominent. Therefore, from the practical significance of English learning, this paper analyzed the causes of the petrification phenomenon of college students' English vocabulary, and found out the corresponding countermeasures according to the reasons.
\end{abstract}

\section{Introduction}

Lexical petrification is an important concept in interlanguage theory and a hotspot in second language acquisition. For most foreign language learners, you will encounter a phenomenon: after a period of time, they reach a certain level, then it is difficult to make significant progress, many of the grammatical errors corrected will reappear after a period of time, it is difficult to be eradicated completely, the foreign language spoke sounds a little "foreign language taste", even those who study foreign language for many years, with abundant vocabulary and grammar knowledge are no exception. This phenomenon is called language lexical petrification. Since the concept of petrification has been put forward, domestic and foreign scholars have carried out extensive research from different perspectives in order to explain this phenomenon, find out the solution to this problem and apply it to teaching and learning practice. The causes of petrification are complex and diverse, and there are many perspectives on research, including physiology, psychology, cognitive science, and cultural society. This paper analyzed the form and characteristics of petrification phenomena which are prone to Chinese learners in English grammar, and discussed the causes of lexical petrification based on the theory of interlanguage and the corresponding causes, and put forward corresponding countermeasures.

\section{Vocabulary Development and Characteristics of Petrification Phenomenon of College Students}

As the foundation stone of the second language acquisition, vocabulary learning has become an important element in the process of English language learning. Therefore, the domestic scholars have made great interest in the development of vocabulary cognitive ability. Through the multilingual study of the word, they made a deep research on the second language of the vocabulary recognition of Chinese students, and referred to Levelt vocabulary internal structure model, the vocabulary acquisition process was refined into three stages.

The first stage is the formal stage. This stage only includes the simple form information of the pronunciation and spelling of the words, and through an indicator to find the mother tongue pairs, to establish the relationship between words and sound. This stage is the entry stage of second language acquisition, accepting vocabulary is far greater than the output vocabulary, China's primary or 
junior high school students are at this stage.

The second stage is the intermediate stage of the mother tongue. With the accumulation of vocabulary, the adhesion between the second language and the mother tongue is strengthened, and the information association between the corresponding words is more direct. In addition, due to the strengthening of vocabulary and grammar learning at this stage, vocabulary acquisition reflects a clear grammar face, learners began to understand the overall structure from the perspective of each use of the law, so the co-occurrence of words was promoted to the focus of second language acquisition, compared with the first stage, the learner's output vocabulary significantly and steadily are improved.

The third stage is called the second language integration stage. At this stage, the vocabulary as a contextual combination is activated, and all the vocabulary information, including form, semantics, syntax and word form, is highly integrated and integrated into the entry.

The actual learning process and the theoretical thrust can not be fully consistent, which has been found and confirmed for a large number of research. Experiencing the rapid advance of vocabulary acquisition in the amount and width at the first stage, stepping into the middle and advanced stages where the vocabulary development significantly slow down, or even stagnant, there "plateau phenomenon", that is, the concept of "interlanguage petrification" proposed by Selinker in its 1972 in the "intermediary of language".

\section{The Main Cause of Lexical Petrification}

The Geographical diffeRences of Things. Because of the different geographical location, many things in China and English countries are different, some English vocabulary in Chinese there is no equivalent words, and some Chinese vocabulary in English is also difficult to find the corresponding word. Chinese students rely on Chinese interpretation of the word, "rarely contact the reality, think about things related to, the results is that they select words based on the Chinese interpretationwhen communicating with the Anglo-American, so that the other side feel inexplicable", misunderstand each other. Such as leek, "Modern High-level English-Chinese Dictionary" gives the meaning of "leek", some people will be understood as "leek", while some people will understand the "onion", in fact, it is very similar to the "green onions" of China. While the leeks Chinese eatdoes not seem to exist in the UK and US market, it can not be equivalent to leek, so the leekis often translated into Chinese onion.

Differences of the Language Itself. Some vocabulary exists in both English and Chinese, while English-speaking people and Chinese have their own customary expressions. For example, the black teathe Chinese people call, while expressed as black tea by English; when Chinese people expressed jealousy to others, will speak "pink eye", while English is green-eyed; Chinese people say "yellow movie", in English itis blue film; Chinese people fear (or cold) will use "goose bumps", while in English it will became goose-flesh, and so on.

The Single Way of Learning. The vocabulary learning method used by Chinese students is a mechanical memory method, often with a glossary of words or a glossary of the vocabulary, "always break away from the frame of pronunciation, spelling, part of speech, meaning". This kind of the memory method by one by one corresponding of English vocabulary to Chinese interpretation, often so that students mistakenly believe that English and Chinese words are completely equal relationship, can not see the mountain bythe blind eye, over time, petrification phenomenon is inevitable, resulting in students using thevocabulary rigidly, the occurrence of vocabulary misuse. This petrification phenomenon is particularly prominent in the Chinese translation and English writing. For example, a student wrote in his essay: Our English teacher asks us to endorse every morning, actually he has regarded the English endorse (endorsement, meaning the back of the signature) and the Chinese "recitation" as the same things.

\section{Counter Measures to Avoid the Petrification Phenomenon}

To solve the problem of lexical petrification, we should first realize that vocabulary learning itself is 
not chaotic, it does exist some rules, there is the possibility of establishing a lexical network.

To Avoid the Mother Tongue Migration. English teaching should pay enough attention to oral teaching. Phonetics valued should be more than vocabulary and grammar. The ultimate goal of learning the language is to communicate, ignoring the voice of teaching will lead to the loss of learning the ultimate goal of the language, and the consequences are serious.

Correctly Handling of Student Errors. Depends on the mistakes themselves. Some of the wrong learners themselves can not be corrected, and if the teacher does not correct them, these inappropriate expressions will remain in the learner's interlanguage until petrification. At this time, the teacher can euphemistically pointed out the error, and told all the students this error is very common and difficult, we should pay attention. So that students will not feel no face, but will be more hard to remember the correct answer.

To Ensure a Sufficient Amount of the best Language Input. By providing an understandable input that is slightly higher than the learner's current level, the learner's language acquisition mechanism can be activated. Therefore, teachers usually pay attention to observe the students in the teaching of learning, to understand their actual language level, in the process of teaching the language, give students understandable and slightly higher than the current level of input of studentsas much as possible. In this way, students are likely to continue to accumulate and try to use language, to overcome the original curing thinking and petrification phenomenon, so that English learning is in the rising state of development. In addition to ensuring that students are provided a sufficient amount of language input, teachers should also pay attention to the best language input.

Textbooks Should Advance with the Times. Textbooks are different from literary works, textbooks have a strong timeliness. Ten years of teaching materials have been gradually unable to keep up with the needs of contemporary social development. Teaching content should be true and reliable, advancing with the times. Pay attention to discipline integration, we can carry out bilingual education, broaden the students' cultural knowledge, to meet their curiosity. Focus on cultivating students' thinking ability, creativity ability and ability to learn independently. Such as more open questions, expand the students thinking. To guide students change from pure imitation, memorable learning into the conscious use of discovery, comparison, analysis, induction, association, understanding, memory and other strategies.

\section{Conclusion}

The study of lexical petrification is of great significance to second language learning. Vocabulary learning petrification is a common phenomenon in English learning when learners reach to a certain extent, but through research on the causes of the petrification phenomenon, we can strive to explore and master some of the measures to prevent, mitigate and eliminate the petrification phenomenon, correcting those mistakes continuously in the study, to correct the petrification phenomenon formed in minds over the years, to restore its true colors, to grasp its true meaning. Learning to use, with secondary school, apply these knowledge, combining the learning and using, and gradually improve the ability level to understand and use language.

\section{Acknowledgement}

Project funding: Nanchang Institute of Engineering Youth Fund (No.: 2010SK027)

\section{References}

[1] Chen J. On Vocabulary Presentation Modes in College English Teaching and Learning[J]. Theory \& Practice in Language Studies, 2014, 4(4).

[2] Chen X. A Tentative Study of Vocabulary Learning Anxiety in College English Learning in China[J]. International Journal of English Linguistics, 2015, 5(1).

[3] Zhang M. An Empirical Study of Applying Associative Method in College English Vocabulary Learning.[J]. English Language Teaching, 2014, 7(6). 
[4] Zhu X A, Dou Y. A Study on Data-driven Learning Model and Vocabulary Self-learning in College English[J]. Journal of Educational Institute of Jilin Province, 2012.

[5] Gan L Y. CALL:The Effectiveness of Application of Vocabulary Learning Program in College English Vocabulary Learning[J]. Journal of Huaihai Institute of Technology, 2013.

[6] Chen J. On Vocabulary Presentation Modes in College English Teaching and Learning[J]. Theory \& Practice in Language Studies, 2014, 4(4).

[7] Zhang M. An Empirical Study of Applying Associative Method in College English Vocabulary Learning.[J]. English Language Teaching, 2014, 7(6).

[8] Mohamed E L. Investigating Difficulties Facing the College of Engineering Students in Learning Specialized English Vocabulary[J]. Sudan University of Science \& Technology, 2014.

[9] Tu Y N, Lin Y F, Chan J C. Constructing a Text-Mining Based English Vocabulary Learning List - A Case Study of College Entrance Examination in Taiwan[J]. 2016, 6(6):43-63.

[10]Cheng Y. Frame Theory and College English Vocabulary Learning[J]. Journal of Chuzhou University, 2015.

[11]Fei W U. An Empirical Study of Happy Class Teaching For Students with College English Vocabulary Learning Disabilities[J]. Journal of Qiqihar University, 2014.

[12] Wang Y, Sun N, University S N. Study on College English Vocabulary Book Based on Memetics[J]. Journal of Huaihai Institute of Technology, 2016. 